\title{
Methodological Approach to Incorporate the Involve of Stakeholders in the Geodesign Workflow of Transmission Line Projects
}

\author{
Francisco-Javier Moreno-Marimbaldo ${ }^{1,2}$ and Miguel-Ángel Manso-Callejo ${ }^{2, * \mathbb{C}}$ \\ 1 Red Eléctrica de España (REE), 17728109 Alcobendas, Madrid, Spain; fmoreno@ree.es \\ 2 ETSI en Topografía, Geodesia y Cartografía, Universidad Politécnica de Madrid, 28040 Madrid, Spain \\ * Correspondence: m.manso@upm.es
}

Received: 24 February 2020; Accepted: 18 March 2020; Published: 20 March 2020

\begin{abstract}
Any artificial infrastructure built in a territory causes changes in its environment, especially when it is a question of large or extensive infrastructures such as high-voltage transmission lines (HVTLs). Such changes are perceived unevenly by the different groups affected or involved. However, all of them can obstruct the development of a project of this type of infrastructure. For this reason, it is increasingly necessary to manage the stakeholders in the different phases of the development of an HVTL project. This article presents the methodological proposal designed to add the management of stakeholders' opinions by integrating it into the geodesign-based workflow for the development of HVTL projects, giving geographic meaning to each of their opinions, allowing their analysis together with the rest of the geospatial information of the project, reusing the "feedback-iteration-consensus" mechanisms, discovering interactions and synergies or incompatibilities, improving the understanding and finally facilitating the consensus of all parties. In this way, it is possible to manage the development of the projects with a single workflow, in which the results are obtained (development stages) and the decisions that are adopted are used both for the technical part and for the management of the project's stakeholders.
\end{abstract}

Keywords: Stakeholders; geodesign; geospatial data; High Voltage Transmission Lines (HVTL)

\section{Introduction}

The implementation of an high-voltage transmission line (HVTL) is a necessary tool in the energy transition that must comply with renewable generation plans. These plans require the development and extension of the electricity transmission grid to guarantee a diversified renewable generation mix, including solar, hydro, wind, biomass, etc., allowing the connection of many producers from small to large, and that adapts to the different territorial characteristics.

This energy transition also implies some social changes [1]. The social perception of renewable generation facilities is positively conditioned by the environmental benefits they produce. However, the power lines that make the renewable scenario possible are conditioned by their negative impacts, especially on the landscape. Unlike what happens with roads or high-speed trains, there is a great contradiction when their social purpose is related to their impact on the environment. For example, high-speed trains are better accepted by the local population than electric lines, despite the fact that their environmental impact is infinitely greater, while their social purpose is less useful. Electricity lines occupy a small area, limited to the land occupied by the pylons, and the destruction of environmental resources is not significant in most cases. They have no barrier effect or fragmentation of ecosystems and no emissions or waste associated with their operation and maintenance are produced. Their impact on physical and biological factors can even be zero. 
The population affected by the construction of an HVTL wants this public service but rejects its implementation. The Anglo-Saxons named this contradiction as the Not In My Back Yard (NIMBY) effect and this was translated into Spanish as the span effect: yes, but not here [1]. The NIMBY effect is the result of a social dilemma characterized by the spatial separation of advantages and disadvantages [2]. To change this perception is a necessary task before the new challenges of the energy transition that requires, as well, the application of new analytical approaches by the degree of complexity that takes place when the economic, social and environmental questions overlap [1]. The problem is not only the implementation of a power line that, a priori, is going to have a visual impact on the environment, but also the possibility of changing the conditions in which humanity and ecosystems have been developing over time.

Until now, it has not been possible to get the different parties interested in this type of project to present their points of view simultaneously, and geodesign provides supporting technologies and design frameworks so that technicians, professional planners and stakeholders can share data and find designs suitable to the characteristics of each territory. As Miller [3] said, geodesign "is design with the territory and for the territory and it aims at contextualized transformation of the landscape, respecting natural and cultural conditions". Neither the administrations nor the agencies/companies in charge of the execution and planning of power line infrastructure have the tools to meet the needs of each profile or stakeholder. The use of planning support systems and decision support systems allows the development of these projects to be redirected towards a new methodology used to refine the corporate geographic information system, in which our geodesign-based workflow of the HVTL [4] is implemented. This allows decisions to be made based on the reality of the territory, and therefore, the new projects will be more solid and organized, efficient and their management and traceability will be more agile. One option proposed by Flaxman [5] useful for planning natural environments, which can be considered as an integral process that consists of several design stages, is the use of geovisualisation technologies. Similarly, Dangermond [6] stated that geo-visualisation allows for the inclusion of geographical analysis in the design process. Therefore, there is a partial convergence between geovisualisation and geodesign. This vision can also be complemented with that of Ervin [7], for whom geodesign applies current technologies that facilitate collaboration by communicating information and improving conventional land planning and design activities. This offers the possibility of simulating on demand and evaluating the impact on the design of alternative scenarios based on scientific knowledge and in a more responsible way.

The management of stakeholders has been, until now, an appendix to the execution of HVTL projects and in a non-systematized way, but at the discretion of the project manager. This study explores the possibility of merging the geospatial information management of this type of project with the management of stakeholders by expanding our previous work [4], incorporating their management in the workflow, and which is supported by the sustainability model of Red Eléctrica de España (REE_ [8]. Figure 1 presents the workflow of the HVTL on which we support the proposal. Its materialization consists of a control panel that automates the execution of the geoprocessing models, the storage of the results and their subsequent consultation. The models generate key facts for the relations with the stakeholders as well as for establishing the action plans.

Our hypothesis is that the use of the workflow based on geodesign for the development of HVTL projects, such as that implemented by REE, will help to manage geographically, and jointly, both the projected assets and those in service, with the stakeholders identified in each case.

Thus, this article sets out to define a conceptual framework and a catalogue of actions sufficient for the management of stakeholders associated with the development and maintenance of HVTL projects. The proof of concept of this conceptual framework is carried out on a set of representative projects developed within REE and is integrated into the geodesign-based workflow implemented at a corporate level. The main contributions of this research work are the stakeholder management methodology integrated in the geodesign-based workflow of the HVTL and its validation with the proofs of concept carried out on a representative set of examples. 
In the following sections, we will address the background and related works on stakeholder management with an internal approach, based on the needs and sustainability strategy of the company [8], and an external one analyzing the management of similar companies. Next, we present the methodological approach that merges with the HVTL geodesign-based workflow creating a new workflow relating to the geographic management of HVTL facilities projects, with the geographic management of the stakeholders of each project. The document closes with the conclusions of the study and the bibliographic references used.

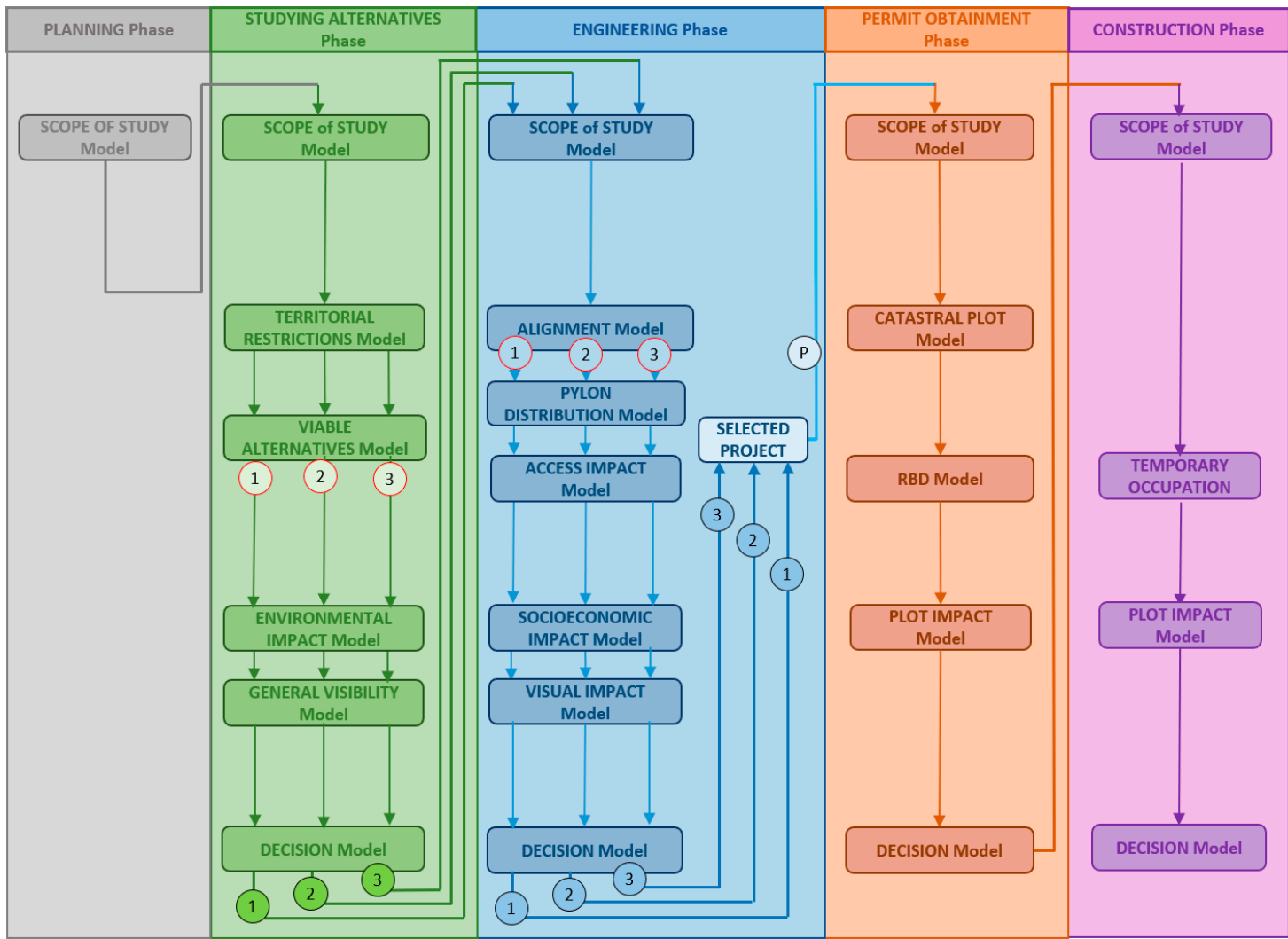

Figure 1. The geodesign-based workflow of the high-voltage transmission lines (HVTL) [4] with the models in each phase of the projects.

\section{Background and Related Works}

Nowadays, the relationships between companies and their stakeholders are increasingly elaborate and there are more and more interactions and greater influence on business by their stakeholders. This reality is enhanced by society's greater demand for information and transparency and the existence of different communication channels.

The identification of the stakeholders of a project and their subsequent classification is vital for proper management in all phases of the project. An electricity transmission grid development project can be summarized in five phases: planning, study of alternatives from the environmental point of view, engineering, obtaining permits and, finally, the construction of the new facility. As indicated in the Project Management Boundary Guidelines [9], a stakeholder is an individual, group or organization that may affect, be affected by, or perceive itself to be affected by a decision, activity or outcome of the project. This guide [9] mentions, as a useful tool for classifying stakeholders, the use of graphs that represent two variables simultaneously to understand how relevant a stakeholder can be, depending on the position in the graph. Specifically, the power/interest matrix, which associates stakeholders based on the level of authority and participation they possess, and also the influence/impact matrix, 
which associates them based on their active participation and capacity to effect changes in project planning or implementation, can be used.

In order to systematize the management of stakeholders in HVTL projects in REE, internal analyses were carried out to collect the different points of view of the actors involved in the projects. Also, the analysis of how the treatment of the stakeholders was approached at national and international level. To this end, information was gathered from the experiences of European TSOs (transmission system operators) and other large entities and companies belonging to very diverse sectors. REE, as a TSO company, participated in different workshops of two projects regarding stakeholder management. In addition, the "lessons learned" from these projects, INSPIRE GRID project [10] and BESTGRID [11] were used. These two European projects were promoted by Renewables Grid Initiative [12]. The INSPIRE GRID project [10] made a classification of stakeholders' types separating their concerns and needs. This classification serves as a starting point for the development of the REE stakeholders' catalogue and the actions to implement them. BESTGRID [11] consolidates the need for close contact between REE and the different involved stakeholders.

\subsection{Internal Analysis}

In recent years, a greater capacity to influence certain stakeholders in the development of HVTL projects has been observed. The same trend has been observed in several European working groups of companies in the sector, which has led to the unanimous conclusion of the need to develop the treatment of stakeholders in a systematic and homogeneous way in the management of projects since it contributes to reduce negative externalities, to identify risks earlier, to detect new opportunities of acceptance of HVTL and, in short, to make its activity more sustainable. Also, in recent years, the corporate geographic information system (GIS) GeoRED has been consolidated in REE as a tool that facilitates decision-making on facilities in project phases or in operation, providing a new point of view for stakeholder management. The company understands stakeholders as those persons, groups of persons, associations or official administrations affected by the services or activities of the company and groups whose opinions and decisions influence the economic results or impact its reputation-similar definition to that proposed by the Freeman working group [13].

Corporate social responsibility (CSR) or corporate communication are concepts that arise from the need for stakeholder management, with the stakeholders themselves and the company's reputation being an important part of the underlying business model [14]. Thus, the need arises for companies to focus on the interests of employees, shareholders, suppliers, customers and related communities to create as much value as possible for the benefit of stakeholders. Corporate communication is conditioned by the strategy of stakeholder management to align it with the company's own strategy for sustainability and CSR [15]. Since 2004, the company has had a corporate stakeholder management model with the mission of "generating shared value and influencing the improvement of the company's reputation", and at the end of 2013 completed its stakeholder inventory, which included only one categorization through the type of relationship with each stakeholder. Its usefulness was restricted to the classification, but it is far from the systematization that it needs.

Given that REE understands sustainability as the commitment to its durability through the creation of shared value for all its stakeholders, the company carried out a review of the stakeholder inventory with the aim of defining it at the group level [8]. As a result, in 2018, it achieved the highest score in the criteria of the Dow Jones Sustainability Index that evaluates the commitment and performance with its stakeholders, having a management model with the mission of generating shared value and influencing the improvement of its reputation. This model incorporates the requirements of reference norms and standards in the field such as AA1000, IQNet SR10, ISO26000 or the Global Reporting Initiative [16]. In this review it defined its commitments to stakeholders and the most appropriate communication channel for each group category [8].

Thus, this corporate management model is based on the principles of transparency, dialogue and mutual collaboration and has as its main elements the identification of the different stakeholders, 
the knowledge of their needs and expectations, the establishment of commitments and relationship frameworks, and the development of evaluation and improvement tools.

\subsection{External Analysis}

From the point of view of the external analysis and after analyzing 31 experiences, other European companies in the electricity sector are noteworthy for their possible applicability to HVTL projects, such as National Grid [17], Eirgrid Group [18], Elia [19], RTE [20], Statnett [21], TenneT [22], 50Hertz [23], Energinet [24] or the INSPIRE GRID [10] and BESTGRID [11] projects. Stakeholder management in European TSOs is oriented towards the generation of trust networks in the medium to long term which facilitates the creation of consensus environments.

In this external analysis, the accessible sources of the consulted entities were revised, although other non-published strategies will probably be developed with the stakeholders. The main lessons learned from this analysis are the following:

- In practically all cases, the importance of beginning to open up to the different stakeholders from the initial phases, including the planning phase, is highlighted, as it is here that the objective justification, understanding and acceptance of the need for and benefits of the electricity transmission network can be transferred to society in general, and to local communities specifically. If this acceptance objective is achieved, agreement on the particular conditions and characteristics of the project is much more attainable. In addition, solutions can be proposed that in more advanced stages are no longer possible.

- In European TSO projects, the action is based on providing a wealth of information adapted to the various stakeholders in their different phases, with emphasis on the issues that are most sensitive for the population: visual-landscape conditions, electromagnetic fields, the environment, etc. Among the lessons learned from BESTGRID [11], it is explicitly stated that "before starting the dialogue and participation it is crucial to offer all the project information to the stakeholders". One of the tools used by several TSOs is the design of a web page per project in which all relevant information is published and which allows to make queries and/or suggestions in a specific way. There are also cases where social network accounts created for specific projects are used.

- The diversity of formats and communicative supports used stands out, from the most conventional ones-meetings, informative conferences or edition of informative material-to the most innovative ones supported by ICT: webs with GIS, social and creative networks: travelling information bus.

- BESTGRID's [11] pilot projects agree in concluding that personal interaction and relationships are the element they consider potentially most important in the success of stakeholder involvement. Their lessons learned insist that even if it is too late to discuss the need for a project, one must always be willing to explain it.

- BESTGRID [11] and the Danish initiative Energinet [24] also persevere that the discussion with stakeholders on the alternatives of corridors, or routes, making explicit the criteria used and on the design of the projects themselves, generates trust and security among them, allowing them to provide solutions from the perspective of local knowledge.

- In the analyzed experiences of other linear infrastructures outside the European scope, strategic work is done on the empowerment of stakeholders (for example, offering training in different subjects related to the expansion of the network, strengthening the capacities of non-governmental organizations so that they can play a role of "external validator", etc.), which generates multiple benefits in the short and medium term.

- The entities that transmit experiences about the participation of representatives of different stakeholders in decision-making, even in complex situations or those of great social sensitivity, value in their dissemination that these initiatives contribute to increasing the credibility and legitimacy of the process [25]. 
- No references have been found where openness and early stakeholder management have generated rejection responses, but it cannot be ruled out that they do not exist. It is very likely that they have occurred but have not been disseminated.

- The lack of a tradition of participation in the planning processes and in the construction of large projects is progressively changing, but it requires a joint learning process by the administrations, companies, the social fabric and the whole population towards attitudes and skills of consensus and collaboration in Spanish society, as is mostly reflected in the international experience.

- The conclusions of the external analysis, in order to develop the new model of stakeholder management proposed, are:

- It is important to start the relationship with stakeholders from the earliest stages of the project by offering homogeneous information, adapted to the different stakeholders and specific to each project throughout its stages (websites, social networks, newsletters, consultation forms...).

- In the international environment, it is considered that good stakeholder management has a very positive impact, not only on the success of the project, but also on the results of its economic management and compliance with deadlines. Furthermore, it contributes to increasing the credibility and legitimacy of the process, and the good reputation of the promoter. This stakeholder management is oriented towards the generation of networks of trust in the medium to long term and environments of consensus. In other words, it is not just a response to social rejection.

- It is considered that it is not sufficient to use information or communication measures and the progress is made towards a model of constructive participation by stakeholders in the decision-making process of a project, which facilitates consensus and acceptance of the facility. In this sense, personal interaction and relations are valued as the most important element for the success of stakeholder management involvement.

Stakeholder management can be considered very incipient in Spain, in relation to other European countries (linked to CSR) and there are not many organizations that have real and contrasted experience in this area. However, the integration of different stakeholders' perspectives during HVTL projects, is becoming increasingly important in the public debate [26].

As regards the applicability of the conclusions, in the most developed European countries in this issue (such as Germany, France, the United Kingdom, Italy and Belgium), society is more accustomed to participating in the changes in the territory that affect them and they have collective experience in dealing with this type of situation. In these countries, there are also intermediary-oriented entities that play an effective role in building consensus between the social interests of the various stakeholders involved and the needs of a public interest project. This is not the case in Spanish society, which has been more passive in expressing collective interests. The reality is that the electricity planning phase in Spain lacks adequate communication of the justification for the need to develop the infrastructure projects contemplated there. Therefore, in order to reduce the risks in the execution of the planning forecasts, it is convenient to make a greater effort to explain and justify the projects, making known their economic, social and environmental benefits. Stakeholders must have early and good justification information, from the first moments in which planning begins to have geographical significance in order to improve its social acceptance. Both the administration that promotes planning and REE, which executes the projects, are interested in this objective. To this end, valid information content must be generated and effective and attractive communication actions must be mobilized.

In order to have a systematic management of stakeholders, it is necessary to create a conceptual framework and a sufficient catalogue of actions for reducing risks in the lack of acceptance and improving the reputation of the entity that knows and respects its stakeholders.

In addition, clear benefits are obtained in the pre-consultation and project design phases, mainly a better risk management in the project and the reputation of the company, when an active participation of the stakeholders is promoted and achieved. This is due to the integration of economic, social and environmental factors in the management, as well as the knowledge of what the project's stakeholders expect and how it will be executed, in the interest of sustainable development. This is one of the 
clear conclusions of this external analysis that can be transferred to the company's operations and to the planning and management assistance systems. It is advisable to disseminate useful, precise and detailed information to the stakeholders that will facilitate their understanding of how the territory will be affected by the executed project. Doubts about the effects of construction or operation should be avoided and irrational fears minimized. In this way, most negative emotional responses can be eliminated.

\section{Methodological Approach}

After the previous analysis, the need for the corporate initiative to give a systematic and overall view of the management of stakeholders of electricity transmission network projects is confirmed. Therefore, the knowledge acquired was applied to a specific proposal. This consists of a flexible methodology for the relationship between stakeholders that offers a joint vision of each project and a set of actions for decision-making for each stakeholder, taking into account current and potential relationships. The final objective of this methodology being the preparation of an action plan for each project, it was important to know the role that each stakeholder has in the project, thus entering into play the classification models of stakeholders of PMBOK [9].

The methodology proposed here to manage the stakeholders has to follow the corporate guidelines, with an integral and scalable vision that is applicable to any type of project and able to be developed and implemented gradually with a vocation for continuous improvement and to facilitate change management.

This type of proposal to include stakeholders in the early stages of projects, in a systematic way, was contemplated by Steinitz in 2012 in his geodesign framework [27], in which he considers "local people" as a fundamental part of the work team.

As a preliminary step, the situation analysis presented was carried out to find out how the company managed its stakeholders and how other companies are doing it. The basic principles of sustainability [8] were then established to guide the stakeholder management methodology to be developed. These principles are internal coordination to transmit messages in a homogeneous manner and with corporate information, active listening to understand the needs and concerns of stakeholders, transparency to generate trust, anticipation to subsequent difficulties and the search for alliances with the stakeholders themselves. This requires clear messages adapted to the message listener, appropriate channels, coordinated dialogue and communication skills.

The proposal combines two main lines of action. The first one is applied at the company's organizational level, through the creation of a new role of corporate stakeholder manager, and the second one is of a technical nature, where the implementation of the methodology translates into tools that schedule its management.

These two lines of action are not independent from each other, but they are related in a workflow that is incorporated, in a parallel way, to the geodesign-based workflow for HVTL through the milestones of the relationship with the stakeholders in each phase.

\subsection{Corporate Stakeholder Manager}

The management of the geographic information of projects is carried out through the geodesign-based workflow for HTVL [4] that establishes geoprocessing models with corporate criteria in the different steps of the project phases. Parallel to the technical management of these phases (environmental analysis, engineering, permitting or construction), another task is carried out to approach the stakeholders of each project phase. This task of intermediation between the technical managers and those responsible for managing the stakeholders is carried out by the new role. Thus, within the geodesign-based workflow for HVTL, they will always be aligned with the development of the project and will manage the action plans to be executed with each one of the stakeholders. One of the functions of this role will be to ensure that the information resulting from the geospatial analyses 
arrives in a systematic way and is understood in a homogeneous way by all parties: technicians, stakeholders and stakeholders' interlocutors.

These stakeholder managers are responsible for identifying and registering the stakeholders in the database as well as their geographic scope of influence. They are also responsible for anticipating and designing action plans with each stakeholder, for giving voice to the internal technical work in a coordinated manner, for generating trust and seeking the necessary alliances, and for maintaining the necessary balance through transparent communication that allows for the anticipation of possible obstacles arising from the relationship with stakeholders. In short, they centralize communications between the technical side and the stakeholders.

Our proposal differs from the one proposed by Flake [28] in that, in their case, they generated a tool for stakeholders to interact with the geographical information of the project. In our case, stakeholder managers use the same GIS as the technicians who analyze and design the project and no different instrument is created to address the social acceptance of projects. In this way, as is the same tool, the company shows its commitment to transparency.

\subsection{Proposed Systematisation}

This proposal addresses the design and implementation of tools to systematize stakeholder management. It is important to adapt methods to tasks, emphasizing the ability to perform trial-and-error iterations to meet the feedback-iteration process [29]. This proposal is composed of five sequential tasks (see Figure 2) and they are applied equally in all the phases of a project, except for the planning phase which has a simpler management. The first of these tasks deals with the identification of stakeholders. This identification is carried out for each project and for each phase of the project. The second task deals with the registration of stakeholders through their geographical area of influence, where it is checked whether the identified stakeholder is already registered. The third task deals with the categorization and classification that each stakeholder has in each phase of each project. The fourth deals with the catalogue of actions to be applied to each stakeholder in each phase of each project, and the fifth deals with the incorporation of stakeholder management in the corporate geodesign-based workflow for HVTL.

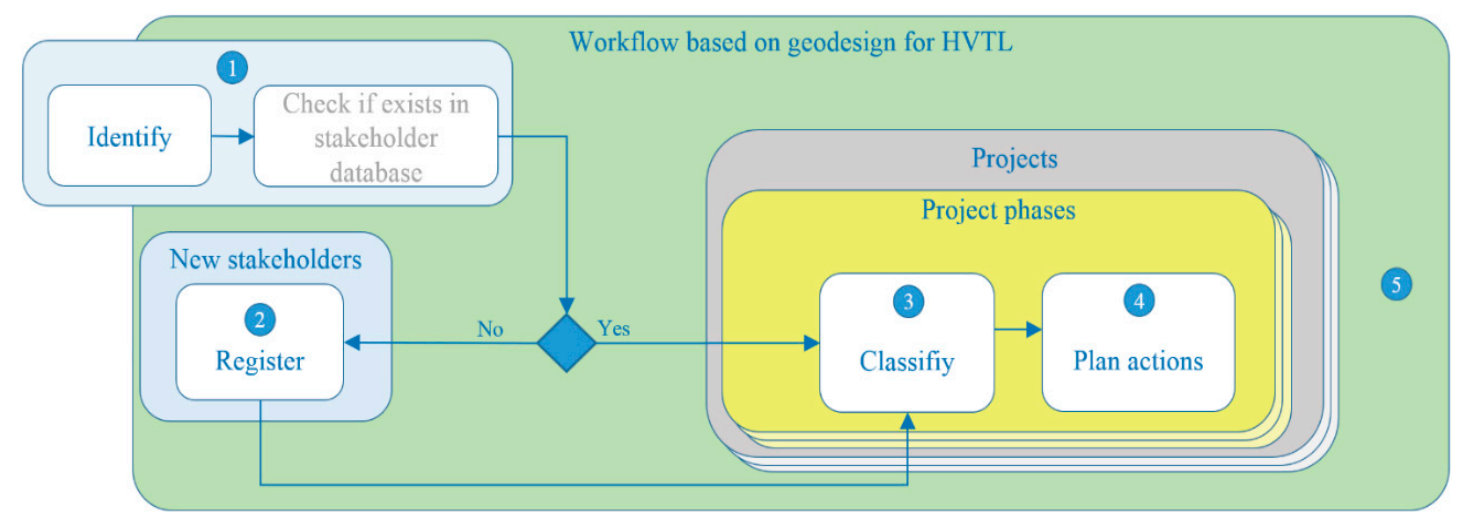

Figure 2. Proposed workflow in systematic stakeholder management.

\subsubsection{Identifying Stakeholders}

According to Cooper [30], stakeholder analysis consists of identifying who the stakeholders are, both existing and future, and the significant relationships between them; what their relationship, interests and views are with respect to the company/action in question; how they might be expected to act (e.g., by facilitating or inhibiting change), how powerful they are and what impact such actions might have; and what the impact of such a stance and actions would be for the company/action in question. At the beginning of each phase of a project, corporate stakeholder managers will identify the 
stakeholders who will serve for that phase and subsequent phases, since constraints on subsequent phases can also be identified.

As indicated by Steinitz [27], local stakeholders have useful information that will help to define solutions, to detect subsequent risks and to anticipate consensus solutions, bringing together the different points of view. By qualifying the stakeholders' definition of the company and the Freeman one [13], we distinguish between active and passive stakeholders. Active stakeholders are those who have the ability to organize, negotiate, reach consensus and change their position regarding a new facility project throughout the project. It is a type of stakeholder directly related to the political and socioeconomic environment of the territory. Passive stakeholders are those most related to the landscape, and the physical and biotic environment of the territory, which will be affected by the mere fact of being where they are. This type of stakeholder is regulated by the current legislation and has a constant position with respect to the project for a new facility.

The INSPIRE GRID project [10] created a detailed catalogue of stakeholders who are generally affected by electrical facilities. In this catalogue, the conditioning factors and concerns of stakeholders with respect to this type of project were also developed. Similarly, the commitment to sustainability in the company's stakeholder management [8] incorporated a list of stakeholders whose grouping categories were equivalent, so that the analysis carried out by the INSPIRE GRID project [10] with regard to the concerns and needs of the different stakeholders was also equivalent. This equivalence served as a starting point so that the catalogue of actions to be applied to each stakeholder responded to their concerns and needs in a way that was aligned with the conclusions of the INSPIRE GRID project [10].

In this methodological proposal, identification is carried out in two different ways. The first is automatic, thanks to the spatial coincidence between the geographical scope of the project and the historical geospatial database of geographical areas of influence of stakeholders that have been identified for other previous projects. This automatic way is possible thanks to the global management of geospatial information that is carried out with the geodesign-based workflow for HVTL. The second way is not manual, but it enhances the presence that the company has in the territory, also in terms of human resources, which leads to contact with local people [27], warning of the needs and concerns of stakeholders regarding the project [31].

\subsubsection{Register of Stakeholders}

The management of stakeholders that are relevant to the development of HVTL projects can be carried out with different approaches. Given the high linkage of these projects with the territory, it was decided to manage them considering their geographical scope of influence as a fundamental parameter, since it can be used to: i) territorially define their geographical area of influence; ii) identify the regions with the influence of several stakeholders; iii) territorially limit the actions to be carried out with each interested party; iv) automate the identification of potential stakeholders for future projects and v) define more targeted actions towards the management of each interested party.

Its registration will be done through its geographical scope that relates the management of stakeholders with the geodesign-based workflow for HVTL. It also allows the identification of potential stakeholders registered for that geographic scope when planning a new installation. Its schedule is integrated in the same geospatial database used for the implementation of the workflow and its management is very simple, by spatial coincidence. In this way, it will also be possible to manage all the descriptive alphanumeric information, as well as the actions to be carried out for each of them.

Each influence scope may be associated with different stakeholders and, in turn, the same stakeholder may be associated with different projects and/or phases of each project. That is there may be ' $n$ ' stakeholders associated with each geographical area of influence, ' $m$ ' actions may be applied to each stakeholders and each action may be related to ' $x$ ' observations. 
Its role will be managed according to the "project-project phase" context. Many stakeholders will have been identified and registered in previous projects or in previous phases of the same project. Only those identified as new will have to be registered.

A way to simplify their management in an HVTL project is to group them by categories, since the management strategies with stakeholders of the same category will be similar. In the same way, the power or interest of each one of them within the same category will also be similar. The list of stakeholder categories proposed in this methodology, aligned with the INSPIRE GRID project [10], can be found in Table A1 of the Appendix A.

The registration of stakeholders is carried out as follows:

1. The geographical scope of influence is appended with its geometries and descriptions

2. For each overlap of the geographical area of influence already recorded in the database by previous phases or projects, it will inherit the associated stakeholders for their alleged influence on the current project with the following information: name of stakeholder, category, project name, project phase, power in the phase, interest in the phase, impact on the phase and dynamism.

3. Newly identified stakeholders who share the geographical scope should be registered and also associated.

4. If the geographic scope of influence is new to the database, the associated stakeholders will also be associated.

Active stakeholders are complicated to model, understand and monitor due to the possible volatility of their position during the project, given the dependence on interpersonal relationships, or their intermittent influence depending on the phase of the project. Their registration involves a field inventory effort in order to understand their concerns and needs [10]. The registration of passive stakeholders is simpler, since most of the download centers of central or regional administrations have the geospatial information catalogued (through metadata) and available. Their registration is direct, and their classification and categorization is immediate and stable over time. This means that thanks to these download centers, the geographical scope of influence is obtained as well as the name and characteristics of each associated stakeholder, such as the SPAs (Special Protection Areas for Birds) which are available for download on the website of the Ministry for Ecological Transition (MITECO).

In order to implement the registration of stakeholders, the use of the corporate GIS (GeoRED) is proposed, by means of a single map service on which to register all the geographical areas of influence of all the phases of all the projects. In this way, the company's geospatial database of stakeholders is obtained. Its use is proposed as it is the logical support for the geodesign workflow in which it is methodologically proposed to be integrated.

\subsubsection{Classification and Categorization of Stakeholders}

Once the stakeholders have been identified and registered, they must be classified according to their characteristics in each phase of each project [32], in order to have the necessary information to systematize their management strategy. This becomes a systems problem [33], since they will indirectly define the scope and functionality of the system. A classification of stakeholders based on their level of cooperation [34] is an incomplete classification; therefore, a strategy to involve them based only on their classification regarding the potential collaboration in the project is insufficient [33].

Each stakeholder is unique in each phase of each project and therefore brings its own perspective with added value to the whole, which is the same as complementarity [35]. In order to determine the management strategies of the different stakeholders, they must be analyzed considering, on the one hand, "the principle of who or what really counts" [36]. The intention behind this is to analyze the stakeholders in the light of the alleged importance that each of them may have. This can be useful to prioritize the actions that are presumed to be most important or most risky for the project. Based on this principle, Mitchell et al. [37] asked "... who (or what) are the stakeholders of the company, and 
to whom (or what) do the managers pay attention?" That is, how do you identify stakeholders and decide how to involve them in problem-solving strategies?

After analyzing and comparing the models for stakeholder management developed by Acuña [38], we propose using a combination of models.

One of these is Mendelow's matrix [39], which classifies and represents stakeholders in the form of a $2 \times 2$ matrix (power-interest matrix, Figure 3) as a tool to assist in their analysis. In this classification, stakeholders are grouped according to their power and interest in the project and its outcome [40]. In order to locate each stakeholder in the matrix, it is necessary to recognize the power they have to modify the course of the project and the interest that each stakeholder has in it.

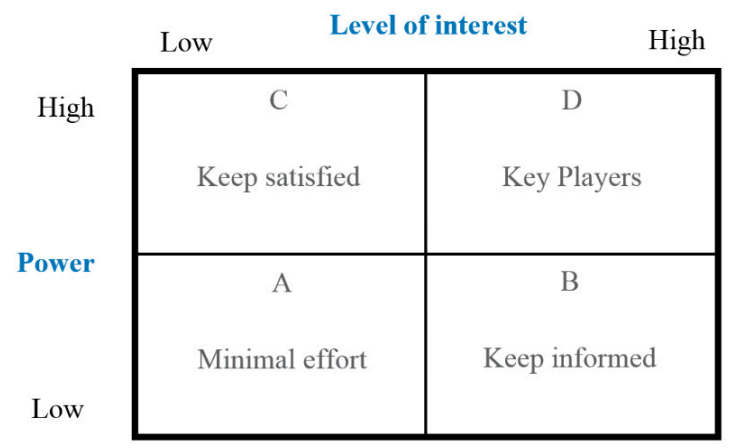

Figure 3. Power-interest matrix (adapted from Mendelow [31]).

Their position in the Mendelow matrix [31], also studied by Gardner and others [41], indicates the type of actions to be taken with each of them. This matrix will help define how communication with them will be managed. The types of actions correspond to the four quadrants of the matrix:

- Quadrant A: Actions to monitor them: stakeholders with low power and low interest that must be monitored and not bored with excessive communication

- Quadrant B: Actions to keep them informed: stakeholders with high interest and low power that must be kept adequately informed and ensure that no problems arise that cause them to change quadrant. These are often very helpful with project details.

- Quadrant C: Actions to keep them satisfied: high-powered and low-interest stakeholders to be kept satisfied, but not so satisfied that they become bored with your message.

- Quadrant D: Actions to manage them carefully: stakeholders with high power and high interest with whom you must fully engage and make the greatest effort to align the project outcome with their concerns and needs [10].

To manage the dynamism or instability of the position that each stakeholder has with respect to the project, there is the power-dynamism matrix [31] (see Figure 4), later studied by Gardner [41]. This matrix will serve to anticipate the consequences derived from a change in the position of stakeholders with high specific weight. Again, the matrix is $2 \times 2$, with four quadrants that the stakeholders are classified in:

- Quadrant A: stakeholders with low power and low dynamism, which will generate few problems.

- Quadrant B: stakeholders with high dynamism and low power, which are unpredictable but manageable.

- Quadrant C: stakeholders with high power and low dynamism, who, being powerful, are predictable.

- Quadrant D: stakeholders with high power and high dynamism, in which greater risks and opportunities can be found. 


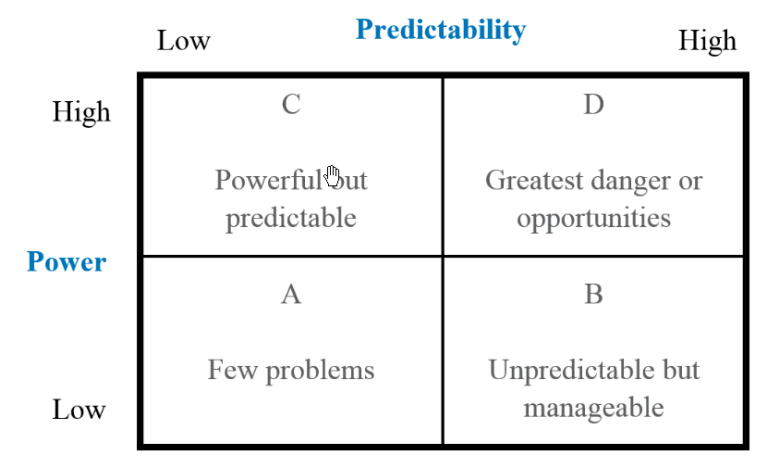

Figure 4. Power-Dynamics Matrix (adapted from Mendelow [31]).

Active stakeholders potentially have a more unstable position towards the project than passive ones.

These changes in stakeholder attitudes have been studied in German power generation technologies [42]. The authors concluded that there is evidence of a polarizing effect of pro- and anti-power plant attitudes that widens the social gap between supporters and opponents. The grouping of opponents can cause serious inconveniences for the development of any project.

In addition, in order to define a more robust stakeholder management strategy, it is advisable to assess the impact that any stakeholder opposition may have on the development of any phase of the project and, therefore, on the overall project.

Considering that the aim is to manage stakeholders within the geodesign-based workflow that manages graphic and alphanumeric data, there are variables that depend on geospatial analysis and others that are characteristic of the project. These variables will help us to define the importance of the project and, therefore, to quantify the impact of each stakeholder on it. Considering that not all projects have the same importance for the company, whether because of their strategic, technical, economic or social aspects, it is advisable to pay special attention to the most important projects.

Considering these four variables used to classify stakeholders-power, interest, impact and the instability of the position or dynamism (Figure 5) - a new matrix is proposed that is capable of representing them simultaneously.

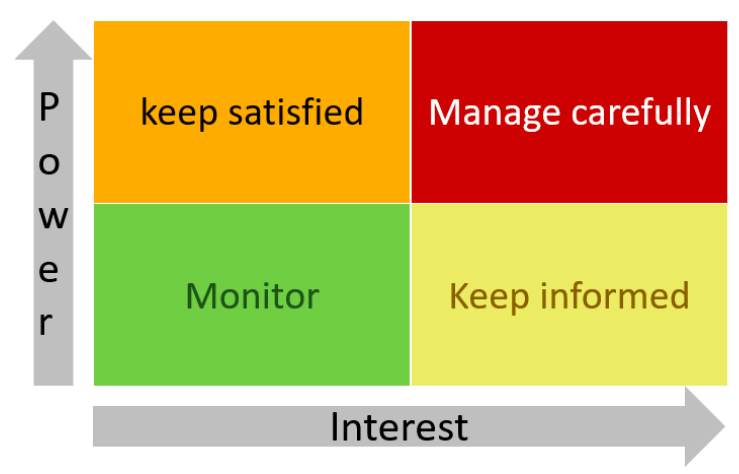

(a)

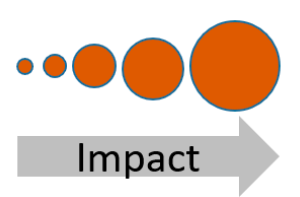

(b)

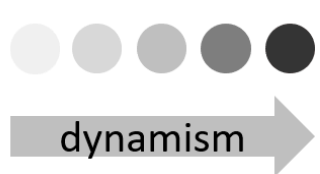

(c)

Figure 5. Symbols to be used to classify stakeholders: (a) variable power (vertical axis) and interest (horizontal axis) for positioning in the matrix (adapted from Mendelow [31]); (b) impact variable shown with the size of the circle which distinguishes which would have the greatest impact and (c) posture instability or dynamism variable represented by the color.

The company responsible for the development of the electricity transmission grid does not have a single strategy for all stakeholders; although the HVTL and its stakeholders belong to the same society and the same environment, they influence each other in different ways [43]. Thanks to this 
matrix, it will be possible to establish different strategies according to the current society in each case; that is, according to the territory and the categories of stakeholders involved in it. In this way, the communication model of any HVTL project with its stakeholders derives from the established communication objectives and the principles of social responsibility of the organization.

In the representation shown in the example in Figure 6, we use the power-interest matrix to represent each stakeholder in the quadrant that will mark the management strategy to be developed with them.

We use the size of the symbol to indicate the impact that each stakeholder can have on the phase of the project in which they have been identified. Finally, we use the color of the symbol to indicate the dynamism or instability of the position. In this way, we have a control panel that allows us to quickly and graphically interpret the type of stakeholder in order to identify the management strategy to be applied.

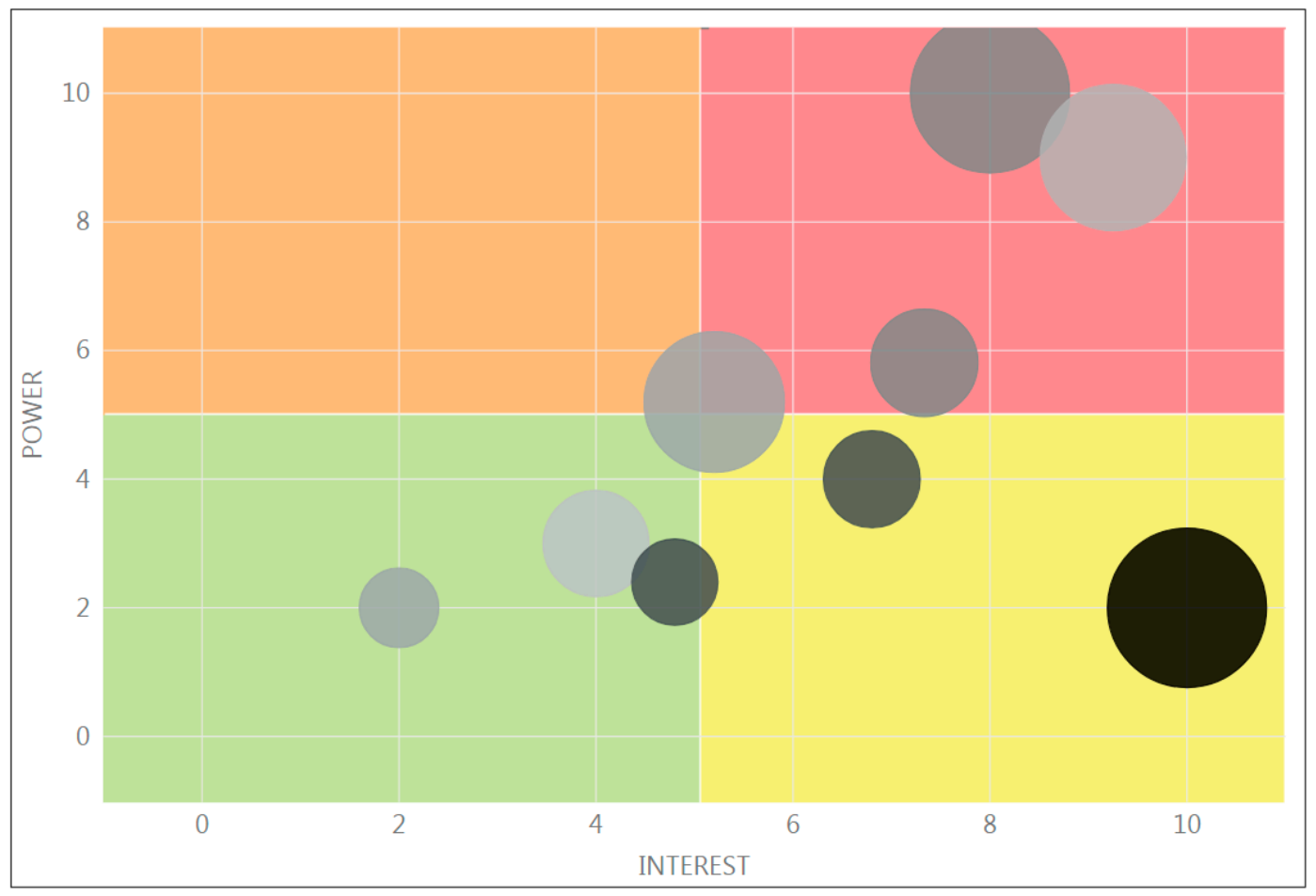

Figure 6. Example of the use of the new matrix, which shows the position of the stakeholder categories in the interest-impact matrix, the impact of some stakeholders with respect to others in the project phase and the instability of the position of each one of them.

Given that, during the projects, a lot of related information is produced and opinions for and against are generated, it is also convenient to consider the instability of the position regarding the project or dynamism derived from the influences that some stakeholders may have on others, favoring a change in their position.

To manage these influences, it is proposed to use a new relationship matrix between stakeholders with moderate or high instability in their position with respect to the project. We will call this the "influence matrix" and it will indicate which stakeholders can influence others and, in turn, which stakeholders will be influenced by the change in the position of others. An example of the influence matrix is shown in Figure 7, in which the direction of the arrow indicates which stakeholder influences the one pointed by the arrow. Sometimes the influence is reciprocal. Again, this matrix is managed and updated by the corporate stakeholder manager. 


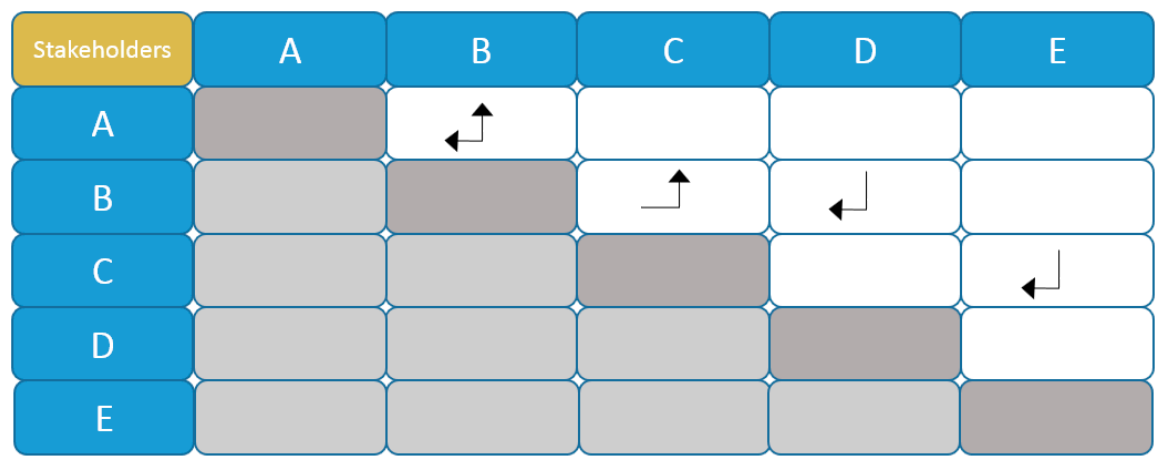

Figure 7. Example of matrix of influences between 5 stakeholders (A, B, C, D and E). A and B influence each other, $B$ influences $C, D$ and $E$ influence $B$ and $C$ respectively. Dark grey cells do not apply (A does not influence A) and light grey cells would be repeating the relationship in white cells (example $\mathrm{AB}=\mathrm{BA})$.

\subsubsection{Cataloguing Actions}

Actions to be taken by the company towards its stakeholders are defined as acts that are carried out for a specific purpose, in a specific area, and that affect, include or are shared with other entities.

Figure 8 shows, by way of example, the results of the execution of the four tasks described: a) the geographical areas of influence of the 13 projects, b) a list of the stakeholders associated with a geographical area of influence of one of the projects, c) a description of one of the stakeholders in the area of influence consulted and d) a description of an action carried out with the stakeholder analyzed.

The catalogue of the types of action designed by the company for the systematic management of stakeholders (see Table A2 of the Appendix A) involves not only having a closed list of actions, but also the monitoring of each action in each phase of each project to verify its success. It is also necessary to have a set of evidence of success to avoid the subjectivity of the classification.

To this end, actions must be associated with each stakeholder in each phase of each project. A stakeholder may have as many actions associated as the corporate stakeholder managers deem appropriate. To associate an action with a stakeholder, the following procedure shall be followed: the stakeholder will be selected from among those registered, a name will be assigned to the action, the phase of the project in which it is applied will be selected, the status of the action will be selected from among the possible ones (planned, in progress, finished or dismissed), and the success of the action will be selected (yes, no or partial), the documentary support will be selected (Table A3 of the Appendix A), as well as the compliance indicator (Table A2 of the Appendix A) and finally the internal person responsible for leading it will be selected, which corresponds to the corporate business units that will be coordinated with the corporate stakeholder manager.

In addition, as many observations or comments on the action as deemed appropriate may be recorded, such as its execution, results or any other aspect that adds useful information.

A pilot test was carried out with 13 electricity transmission grid development projects. These projects were selected in different environments and at different stages to detect problems and improve methodology.

The fifth task will be executed through the geodesign-based workflow in which the results of the execution of its models will provide the corporate stakeholder manager with the necessary information to manage them. 


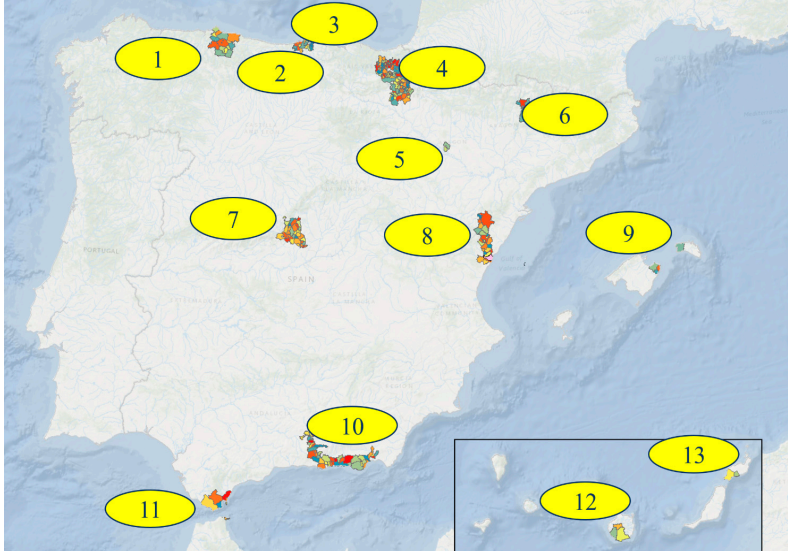

(a)

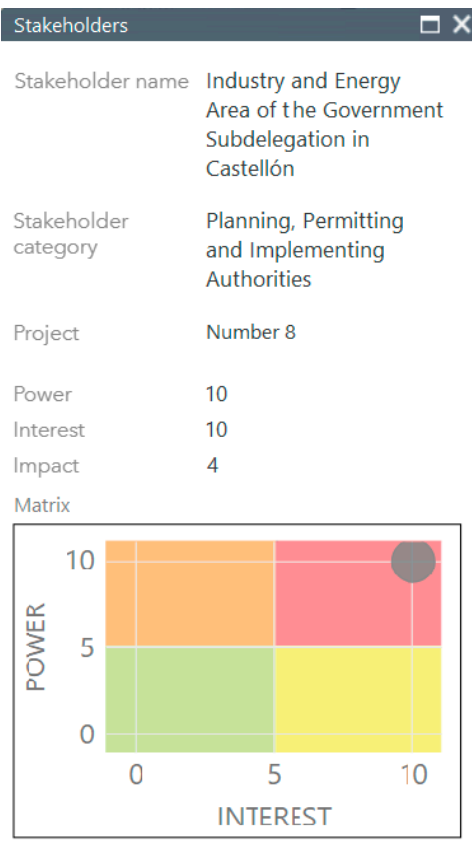

(c)

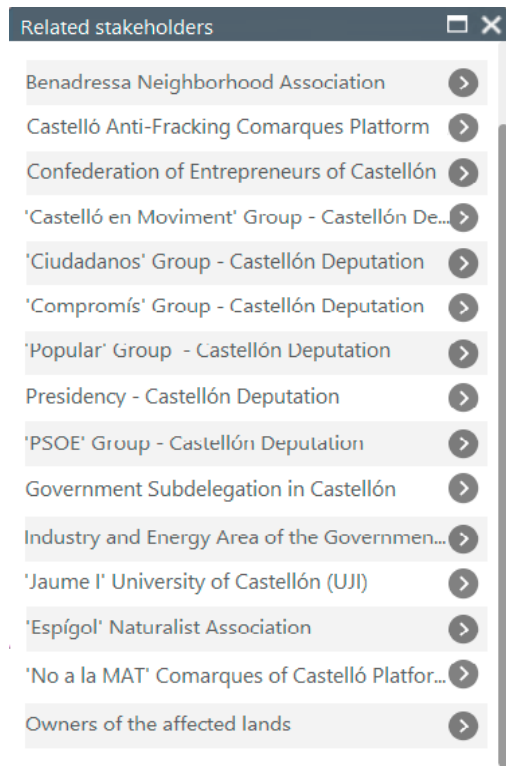

(b)

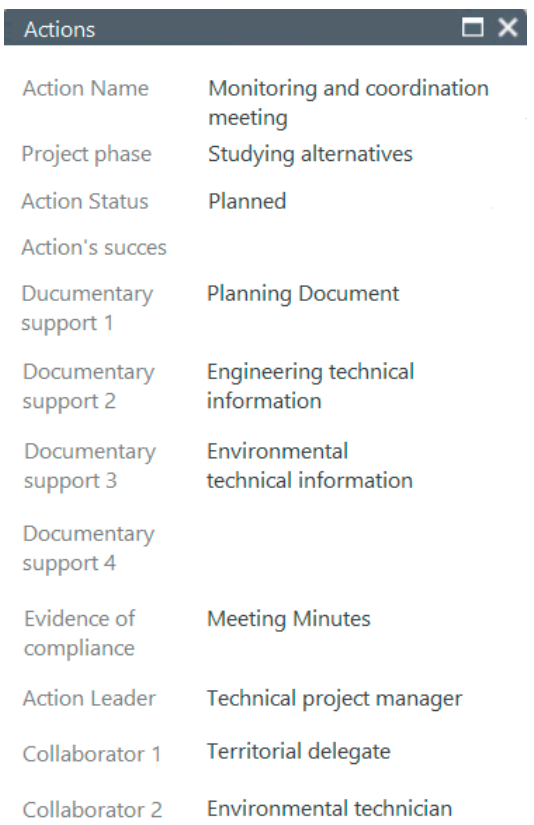

(d)

Figure 8. (a) Geographical areas of influence of the 13 projects managed with the proposed methodology; (b) list of stakeholders associated with an area of influence; (c) description of a stakeholder; (d) example of action with a stakeholder.

\subsubsection{Stakeholder Management in the Geodesign-Based Workflow for HVTL}

The proposed geodesign-based workflow for HVTL is continuously evolving. With the methodological proposal for the management of the stakeholders, changes are introduced in the workflow to identify them, and to manage the collaboration and consensus with the stakeholders related to the project. These changes are introduced in different points of the workflow because, as in the Steinitz framework [27], applying the models of our geodesign-based workflow and involving the stakeholders of the territory (feedback-iteration-consensus), we can know the territory, the determining factors, the processes that operate in it, the changes that the project of a new installation will cause in that territory and its impact. In this way, it will be possible to anticipate and favor the willingness of 
the stakeholders to undertake any type of action as the project is taking shape. It is therefore a question of moving from stakeholder management to a commitment to them [44].

Using the geodesign-based workflow as a reference base, three stakeholder management milestones are established in each phase, except in the planning phase.

The first of these, considering that the first of the workflow models is related to the scope of the study, addresses i) the automatic identification of geographical scopes of influence of previously registered stakeholders; ii) the registration of new ones; iii) the classification of each stakeholder in each phase; iv) the action plan or assignment of actions. In other words, the workflow described in Figure 1.

The second management milestone, considering the results of the analyses carried out by the different models in each phase of the workflow, tries to keep each stakeholder involved in the progress of the project since each model executed will add more useful information to better understand how the final design of the project is being carried out. This milestone is a collaborative process of feedback-iteration to align the expectations of all parties to be managed by the corporate stakeholder manager. An example of this milestone can be seen in the permitting phase, where an access road to a future pylon can be designed on one side of a plot and, after the feedback process established with the land owner, a new access road is designed that is satisfactory to both parties.

The third management milestone seeks consensus on the outcome of each phase. That is, in the workflow, each phase is finalized with a decision model; this decision is made based on the results of the technical analysis and the results of the desired consensus with each stakeholder.

Figure 9 shows graphically the entities that compose it and the merger of the geodesign-based workflow for HVTL, with the proposal for geographical stakeholder management presented in this article.

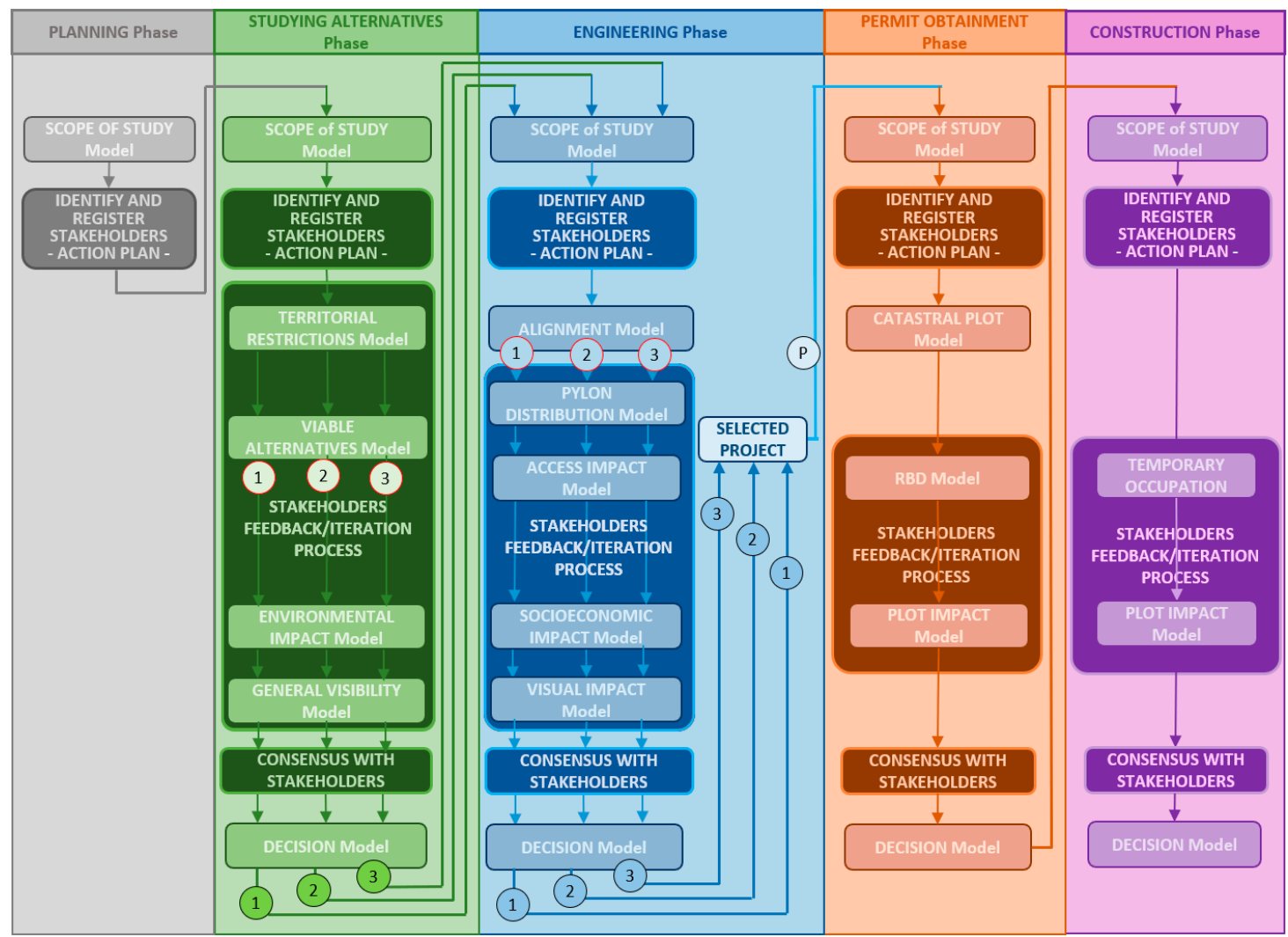

Figure 9. Merging the geodesign-based workflow for HVTL, with the proposed geographic stakeholder management. Boxes in soft color are from the geodesign-based workflow for HVTL and boxes in dark color add the new functionality. 


\subsection{Integration of Stakeholder Management in the Workflow}

Stakeholders are not directly involved in the decision-making process of the HVTL projects, but it is important to understand how to involve them in the feedback-iteration processes, combining their participation with the different models of change proposal and evaluation of its impacts taking into account their needs. This is a key point to bring the technical and social field closer, thus reducing the distance between the technical analysis and the non-professional evaluations carried out by the stakeholders [45].

The management of the different stakeholders in each phase of the HVTL project, as defined by the geodesign-based workflow, will be carried out as follows:

\subsubsection{Planning Stage}

The main national energy needs are the main triggers of the planning phase: the sizing and meshing of the electricity transmission network to ensure security of supply, the evacuation of the facilities where it is generated, industrial consumption and the supply of high-speed railways.

This is a phase in which the scales of work are small and the stakeholders coincide with the promoters, so that the consensus is absolute and there are hardly any points of friction.

Our methodology proposes a single stakeholder management milestone that addresses their identification and geospatial registration. Once registered, they will be associated with this phase of the project and an action plan will be designed, based on the actions defined in a corporate way [8].

\subsubsection{Study of Alternatives stage}

In this phase, energy interests are confronted with territorial constraints. Three management milestones are proposed for the stakeholders. Firstly, their identification and geospatial registration associated with this phase. In addition to the new stakeholders, those registered in the planning phase can be involved in this phase. The action plan designed at this milestone for each stakeholder will be based on the actions defined in the corporate model for relations with stakeholders (see Table A2 of the Appendix A), which will be refined on the basis of the success history of the actions carried out with each stakeholder and in that territory. Secondly, after the analysis and territorial diagnosis and during the study of viable alternatives, a feedback process will be started with the stakeholders to make the technical solution compatible with their requirements. As the geodesign-based workflow is defined for HVTL, this iterative process will use the model that evaluates the possible environmental impact of each alternative and the model that evaluates the visibility of each one of them. Intrinsically to this iterative process, the actions already mentioned will be executed in order to adequately manage each stakeholder in this phase of the project.

Thirdly and finally, after analyzing the environmental and visibility impacts of the resulting corridors, the corporate stakeholder manager will convene a meeting in which the information already provided in the previous feedback milestone will be reviewed and the consensus of all parties will be sought, in order to conclude the alternatives study phase, resulting in at least three corridors in which the project's engineering solutions will be analyzed. In this phase, passive stakeholders take on greater relevance, since they are usually the environmental protection figures that are regulated and respond to official regulations. Their identification, registration and association with this phase of the project can be assumed as automatic.

\subsubsection{Engineering Stage}

The engineering phase has as its entrance the three viable corridors of the alternatives study phase. Three engineering projects will be carried out. This phase also includes three milestones for stakeholder management. In the first one, the stakeholders of this phase will be identified and geospatially registered, and the stakeholders will be associated with this phase. Each stakeholder has a different relevance according to the phase of the project and, therefore, their position in the 
power-interest matrix or their characteristics of impact and stability in their position with respect to the project will also be different. The action plan will also be established based on the actions defined in the corporate model of stakeholder management, which will again be qualified by the history of success of the actions carried out with each stakeholder for that same territory. The relationships established with the stakeholders in the previous phases of their involvement will be taken into account.

The second milestone corresponds to the first sketch of the spatial distribution of the pylons of the future power line, with which a feedback process will be initiated again, using it as a tool for the analysis and communication of the geodesign-based workflow model for HVTL, where the socioeconomic and visibility impacts of the pylons are analyzed. Afterwards, the necessary actions will be executed to adequately manage each stakeholder in this phase of the project. After this iterative process, the third milestone corresponding to the consensus will be undertaken. As in the Steinitz geodesign framework [27], this consensual solution usually involves a negotiation that satisfies all parties. The effectiveness of the corporate governance of any company will be greater when more stakeholders understand each other associated with its activity, which will improve its corporate reputation and productivity. Companies that nurture and train their staff to work with stakeholders through understanding sessions will be more socially responsible and innovative than those corporations where only corporate discussions take place [46]. At this point, after the third milestone, it is decided which alternative associated with a corridor and engineering phase will be built. Any change in the layout that arises from this moment can mean redoing a large part of the engineering work that consists of the territorial effect as well as the electrical and mechanical component of the project. For this reason, it is very important that there is only one solution agreed upon by all parties.

\subsubsection{Obtaining Permits Stage}

In this phase, the scale of work approaches the resolution of the cadastral parcels and the stakeholders are mostly the owners of the affected parcels. If there is no other HVTL project crossing the same territory, the stakeholders will be new and will have to be identified and registered. The service of the Electronic Cadastral Headquarters [47] provides the geospatial scope of influence and the name of each one of them, fulfilling the first milestone of stakeholder management in this phase. The action plan will be very similar for most of the stakeholders in this phase derived from their profile as owners of affected plots, and is defined in the corporate model of stakeholder management.

The second management milestone for these stakeholders will begin with the publication in the official media or local news media of the effect of the future electrical installation on the plots of land they own. Once informed, a personal meeting will be held to provide more detailed information on how the new installation will affect the plots of land they own, and where the dimensions of the easements necessary for the correct use and maintenance of the future facility will be quantified. In this iterative process, the models, as defined by the geodesign-based workflow for HVTL, will be used to assess the impact of the future facility on the cadastral parcels. The actions in this phase are the most related to the local people [27], who will live with the facility.

The third milestone will address the mutual agreement with the corresponding economic compensation for the easements acquired and quantified previously.

\subsubsection{Construction Stage}

In this phase, the stakeholders have been identified and registered previously, so the first management milestone is simplified in terms of the research needed in other phases. The new stakeholders are related to the temporary occupations needed for the work, which derive from the needs for access or collection of material not contemplated during the project. For them, the action plan will consist of an extension of the plan applied in the permitting phase. The second milestone of stakeholder management is associated with the quantification of the actual damage caused to the plots, their vegetation and/or buildings during construction. This milestone will not be iterative since, thanks to the geodesign-based workflow models for HVTL, the real magnitude of the damage caused by the 
construction of the facility will be calculated, thus being able to dimension the economic compensation to be applied. The third milestone will serve to financially compensate for the damage caused.

Although in this phase the project designed in previous phases is materialized, it is necessary to manage different stakeholders from all the phases. A problem in the construction phase could result in high cost overruns [40] or failure to meet deadlines in projects whose commissioning may be strategic.

\subsubsection{Summary of the Integration of Stakeholder Management into the Workflow}

It is in this geodesign-based workflow for HVTL where all the previous phases of the methodological approach are joined and which serves to feed back the process when faced with a new project that crosses a territory already analyzed. That is, a stakeholder previously identified in another project, in any of its phases, will be automatically identified as a potential stakeholder for a new project that overlaps geographically with it. In turn, any action carried out in the past with that stakeholder in that territory will have a success rating. This will make it possible to guide the strategy to be applied in every project with it.

The proposal highlights the importance of characterizing and categorizing each stakeholder (power, interest, impact and stability of each stakeholder's position) with respect to the project. It also highlights the importance of identifying the interrelations between the stakeholders of each project, of associating the actions by stakeholder and phase of the project and, furthermore, the importance of visualizing the entire action plan as a whole for revisions and adjustments.

\section{Discussion and Results}

The 13 projects selected are representative of both the diversity of facilities and relations with the territory. In Table 1, we present a summary of the management with the new methodology. The names of the projects have been coded by the company's desire.

Table 1. List of projects analyzed, project phase detailing the set of registered stakeholders and the actions carried out with them. The legend for project phase is SA=Studying alternatives; $\mathrm{CO}=$ Construction. The legend for project type is $\mathrm{OL}=$ Overhead line; $\mathrm{UL}=$ Underground line; SE = Substation; $\mathrm{SL}=$ Submarine line. The last row expresses the sum of the topics written in the heading, except for the column '\# of different Categories', which expresses the number of different categories registered in the 13 projects.

\begin{tabular}{|c|c|c|c|c|c|c|c|c|c|c|c|}
\hline 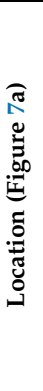 & 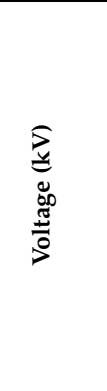 & 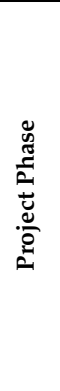 & 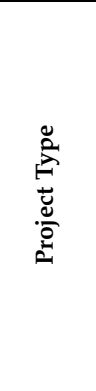 & 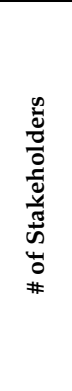 & 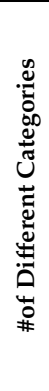 & 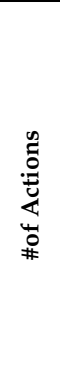 & 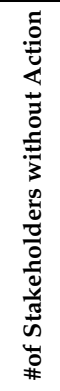 & 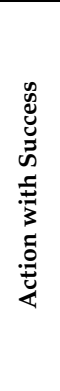 & 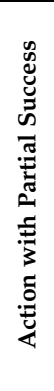 & 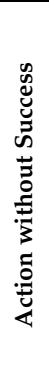 & 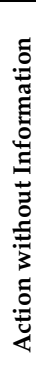 \\
\hline 1 & 220 & SA & OL & 39 & 11 & 39 & & 29 & 2 & 4 & 4 \\
\hline 2 & 220 & $\mathrm{CO}$ & OL & 67 & 13 & 11 & 56 & 9 & & & 2 \\
\hline 3 & 220 & $\mathrm{CO}$ & OL & 72 & 13 & 6 & 66 & 4 & & 1 & 1 \\
\hline 4 & 400 & SA & OL & 432 & 11 & 407 & 25 & 296 & 75 & 16 & 20 \\
\hline 5 & 220 & SA & UL & 36 & 13 & 36 & & 22 & 4 & 4 & 6 \\
\hline 6 & $220-400$ & SA & $\mathrm{SE}$ & 39 & 8 & 39 & & 26 & 5 & 2 & 6 \\
\hline 7 & 400 & SA & OL & 34 & 10 & 6 & 28 & 3 & 1 & & 2 \\
\hline 8 & 400 & SA & OL & 58 & 9 & 25 & 33 & 17 & 3 & 2 & 3 \\
\hline 9 & 132 & $\mathrm{CO}$ & SL & 94 & 9 & 85 & 9 & 55 & 13 & 7 & 10 \\
\hline 10 & 220 & SA & OL & 21 & 8 & 21 & & 16 & 2 & 1 & 2 \\
\hline 11 & 132 & SA & UL & 55 & 9 & 55 & & 29 & 21 & 3 & 2 \\
\hline 12 & 220 & SA & $\mathrm{SE}+\mathrm{OL}$ & 60 & 10 & 46 & 14 & 31 & 1 & 5 & 9 \\
\hline \multirow[t]{2}{*}{13} & 220 & SA & SL & 34 & 9 & 19 & 15 & & & & 19 \\
\hline & & & Sum & 1041 & 15 & 795 & 246 & 537 & 127 & 45 & 86 \\
\hline
\end{tabular}


These projects have been analyzed in the environmental study of alternatives phase and in the construction phase. This depends on the phase of the project at the time of analysis. In the projects whose status is construction, the stakeholders of the previous phases that have relevance in that phase are incorporated. The table quantifies the number of stakeholders identified, registered and catalogued in their corresponding categories. It also shows the number of actions carried out and their assessment of success.

In some projects, the actions assigned to stakeholders are not available due to their state of progress. Those responsible for leading the actions to be carried out with the stakeholders are the ones who carry out the success evaluations. These are the people responsible for the company's organizational units, who are fully coordinated with the corporate stakeholder manager. In aggregate, these 13 projects show a success rate of $68 \%, 16 \%$ partial success (either because the result was not totally satisfactory or because the action was not completed and remains open), 5.7\% unsuccessful actions and $11 \%$ unvalued actions.

The distribution of the 1041 identified and recorded stakeholders is in the matrix showing the variables power, interest, and impact, in Figure 10.

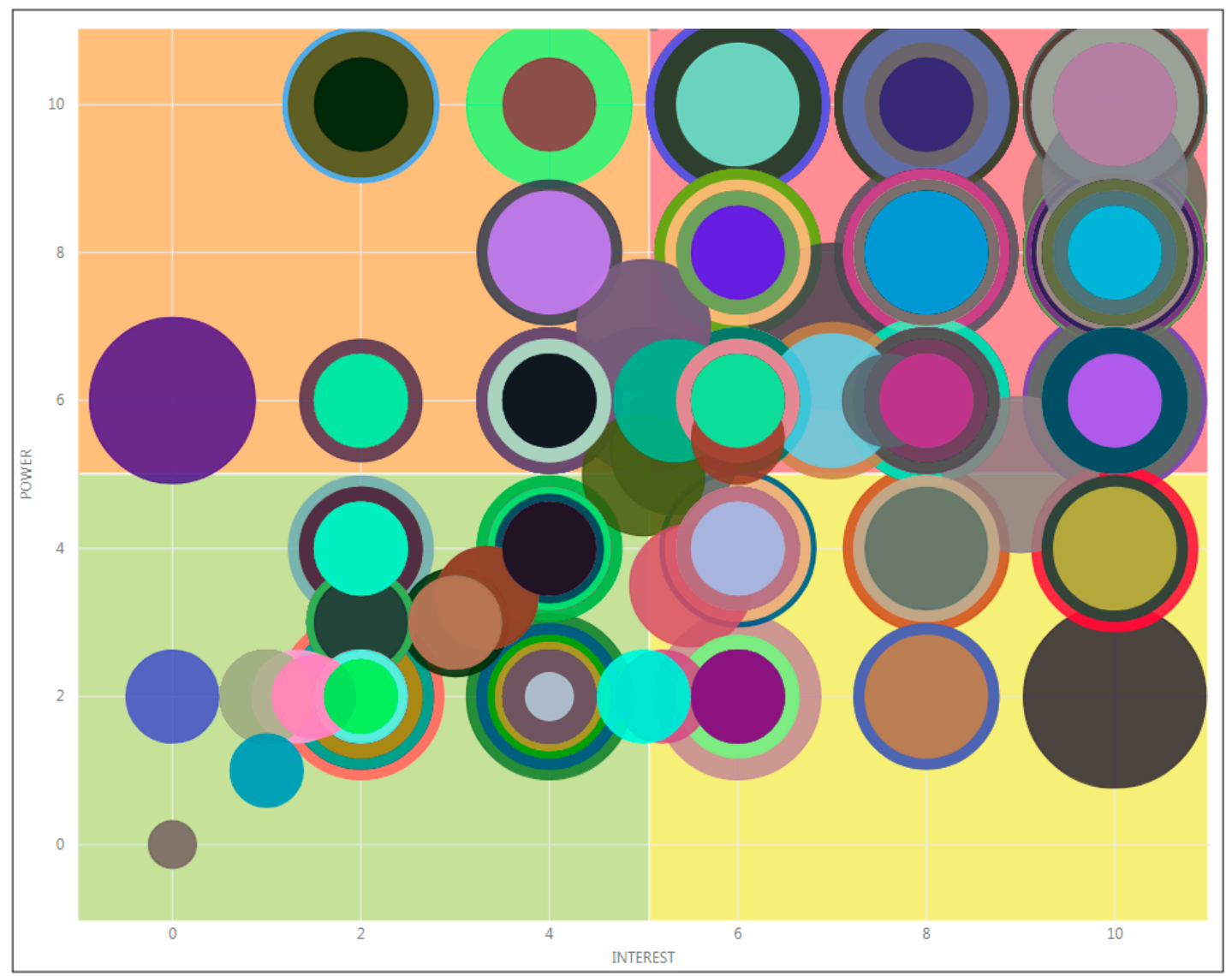

Figure 10. Representation of the power-interest-impact matrix of the set of stakeholders analyzed in the 13 projects.

This does not show the variable stability of the position or dynamism due to the high agglomeration of stakeholders that would make its interpretation difficult. It is observed that there is greater agglomeration in the upper right quadrant, where the impacts are also large.

If we analyze only one project, number 8 (see Table 1 and Figure $8 \mathrm{a}, \mathrm{b}$ for its dimensions and location, respectively), we can see in Figure 11a a similar distribution of stakeholders in the power-interest matrix to that of the set of projects. The stakeholders of large impacts are also concentrated in the upper right quadrant. 
With regard to the categories of these stakeholders, those with the greatest impact are located in the right quadrants of the matrix (see Figure 11b), with special concern for political associations, town councils and the media as major opinion makers who can influence stakeholders in their own and other categories.

Analyzing the actions carried out, it can be seen that their behavior is in line with the average of the 13 projects, with $68 \%$ success, $12 \%$ partial success (either because the result was not totally satisfactory, or because the action has not been completed and remains open), $8 \%$ unsuccessful actions and $12 \%$ actions not yet evaluated.

Analyzing the stakeholders with whom the action carried out was not successful, or had partial success, we observe that in both cases they were of the city hall and Planning, Permitting and Implementing Authorities type (see Table A1 in the Appendix A).

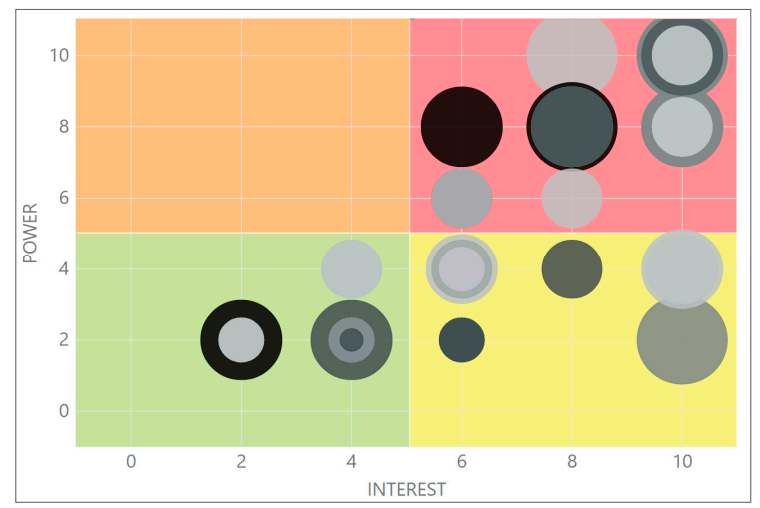

(a)

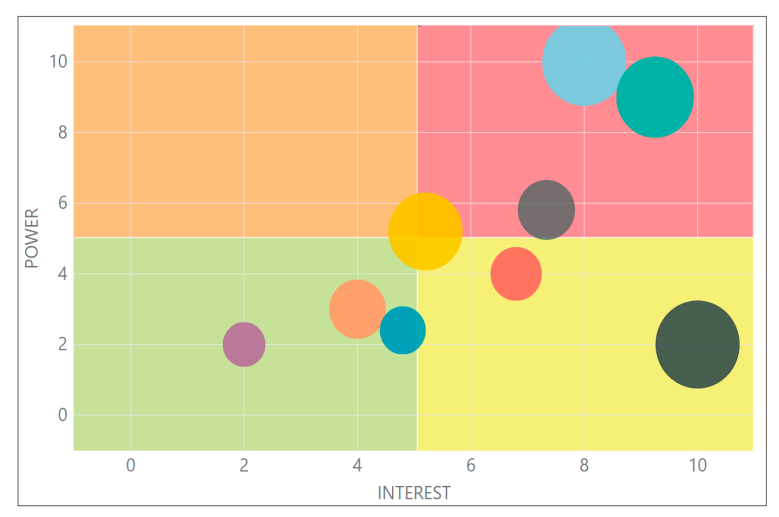

(b)

Figure 11. Representation of project $n^{\circ} 8$ matrixes. (a) Representation of the power-interest matrix position, and impact and stability of the stakeholders. The names of the stakeholders are not relevant to show their distribution in the matrix. (b) Average value matrix of the power and interest variables. The impact variable is shown using the size of the project's stakeholder categories; The legend of categories is as follows: City halls; Land Owners, Forest Owners and Farmers; Nature Conservationists; - Opinion makers; - Planning, Permitting and Implementing Authorities; Political associations; Professional and business associations; Scientific and educational entities; Social agents.

One of the actions carried out with the stakeholder city hall of the municipality with code 2037, which has been an "Informative meeting and/or to collect contributions" (see Table A2 of the Appendix A) is surprising because of its negative assessment, since the territorial impact is small, as the future HVTL passes near the municipal boundary.

This stakeholder requested that, considering that the future substation (end of the HVTL) will be in the adjacent municipality (see Figure 12, code 2068), the route be moved to the latter territory.

This is not the case with the stakeholder representing the municipality that borders the south (see Figure 12, code 2030), which understood that the orography and environmental impact are more complicated in the other municipality (see Figure 12, code 2068) and accepted the proposed route.

City halls are in the 'manage carefully' quadrant of the matrix with high impact, and this situation was caused by a lack of coordination of action plans. The 2037 city council was informed by the neighboring municipalities and not by the project promoter. After a second informative meeting with details of the project and after a negotiation, the trace proposed by this municipality was authorized. Figure 12 shows the route of the future HVTL as it passes through the municipalities mentioned. 


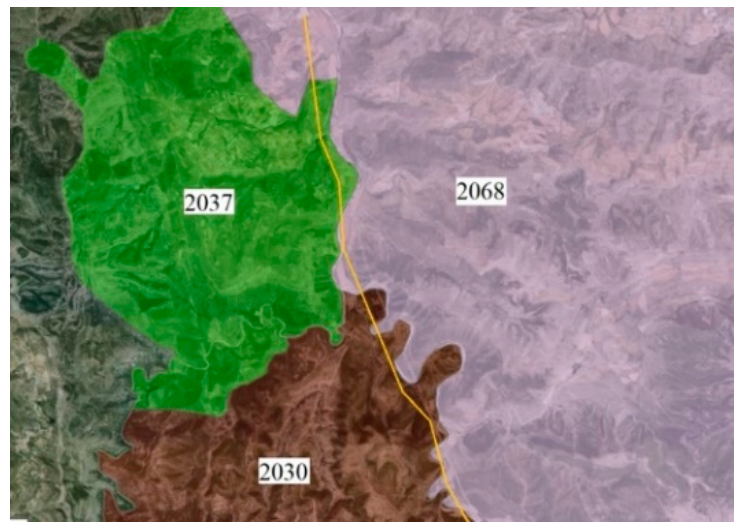

Figure 12. Proposed route of Project number 8, as it passes through the municipality 2037.

\section{Conclusions}

The models and the geodesign-based workflow for HVTL [4] defined in previous works guarantee that the projects are developed using the same corporate criteria, minimizing the use of personal criteria of the technicians in each phase and obtaining more homogeneous and sustainable results. It is a reality in corporate GIS (GeoRED), which already allows us to represent and establish collaboration scenarios and apply geoprocessing models in an iterative way. These models respond to processes that, from a technical point of view, result in the execution of geoprocesses whose results describe the future facility from different points of view.

The geographic management of stakeholders allows treating the geospatial information that represents them as another of the variables to be taken into account in the development of HVTL projects. It allows the integration of stakeholders with strategic, technical, economic, social and environmental factors in the management, seeking sustainable development. In this way, the risk and reputation of the company can be controlled, as the activity and value contributed is made known by improving information and access to it for stakeholders, and the identification of interlocutors, perceptions and attitudes of stakeholders in a new project for the development of the electricity transmission network is favored.

The incorporation of stakeholder management in parallel with the execution of the geoprocesses allows the information generated by the geoprocesses to be shared with the different stakeholders at the time it is generated. In this way, stakeholder management is also systematized and homogenized. They will be identified, classified and associated with an action plan, and will be considered an integral part of the iterative processes, seeking consensus in accordance with corporate criteria.

The main research objective of this contribution has been to define a conceptual framework for the management of stakeholders associated to the development and maintenance of HVTL projects and a sufficient catalogue of actions. In Section 3, the methodological proposal for the integration of stakeholder management with the geodesign-based workflow for HVTL has been developed. As a proof of concept of this conceptual framework, the results of applying this proposal to a representative group of projects developed within the company have been presented and discussed. It has been shown how the integration of its management based on GeoRED and some auxiliary tools that facilitate the exploration and visualization of the dimensions of the decision matrixes and the symbology proposed and adopted, at a corporate level, has been carried out.

After integrating stakeholder management into GeoRED, the latter allows users outside the organization to collaborate with the technicians responsible for the projects through their corporate managers. The incorporation of stakeholder management in the HVTL geodesign-based workflow enables stakeholders' interlocutors to find their own workspace in which, simultaneously with the execution of the geoprocesses, they can express their opinions regarding each of the results, forming part of the iterative process in which all stakeholders will collaborate to facilitate consensus. 
Thanks to this exercise in transparency and collaboration, the company applies an action plan designed and supervised by the corporate manager for each of the stakeholders identified and classified at the beginning of each phase of the project. This plan is executed in the form of actions that are induced by the position that each stakeholder holds in the power-interest matrix, the impact that it may have on the project, and the stability of its position. This requires monitoring, more or less intensely, to ensure that the type of actions assigned are the most appropriate.

The figure of the corporate stakeholder manager stands out as a relevant facilitator in the geodesign-based workflow for HVTL, since it materializes and centralizes the dialogue that internally accompanies the technical development of the projects and externally transmits the sensations of the stakeholders as the development phases of the projects advance.

This ensures that project management is unique both for the technical part and for the stakeholders, since the execution of the models feeds both the technical processes and the arguments that help to explain the project to the outside world.

The methodology has been applied to 13 projects distributed throughout the country and of different types: aerial, underground, submarine and mixed. The trial with these projects has allowed us to improve the methodology and to validate it, initiating the change towards a more sustainable way to undertake the projects of development of the electrical energy transport network. The whole methodology developed for the context of HVTL projects can be applied (with adaptation) to other linear infrastructure projects such as oil and gas pipelines, railways, etc. In all of them, in addition to the different technical iterations, there is a strong relationship with the stakeholders to facilitate their development.

All this shows a strong institutional commitment to sustainability (social, technical-economic and environmental), aimed at supporting the development of society and the conservation of its natural capital.

Author Contributions: Conceptualization, Miguel-Ángel Manso-Callejo and Francisco-Javier Moreno-Marimbaldo; Methodology, Francisco-Javier Moreno-Marimbaldo and Miguel-Ángel Manso-Callejo; Software, Francisco-Javier Moreno-Marimbaldo; Validation, Francisco-Javier Moreno-Marimbaldo; Formal Analysis, Francisco-Javier Moreno-Marimbaldo and Miguel-Ángel Manso-Callejo; Investigation, Francisco-Javier Moreno-Marimbaldo; Writing-Review \& Editing, Miguel-Ángel Manso-Callejo and Francisco-Javier Moreno-Marimbaldo; Supervision, Miguel-Ángel Manso-Callejo. All authors have read and agreed to the published version of the manuscript

Funding: This research received no external funding.

Acknowledgments: Authors want to make a special mention of the project team on stakeholder management carried out in 2018 at Red Eléctrica de España. This project team was multidisciplinary in nature as technicians from different specialities and organizational units participated. This project has served as a basis for developing the methodology proposed here.

Conflicts of Interest: The authors declare no conflict of interest.

\section{Appendix A}

Table A1. Stakeholder categories.

\begin{tabular}{c}
\hline Stakeholder Categories \\
Broad Public \\
City halls \\
Companies in the same sector \\
Construction Companies \\
Energy Providers and Producers \\
Land Owners, Forest Owners and Farmers \\
Nature Conservationists \\
Non-Governmental Organizations \\
Opinion makers \\
Planning, Permitting and Implementing Authorities \\
Political associations \\
Professional and business associations \\
Public entities \\
Residents \\
Scientific and educational entities \\
Social agents \\
Tourism Industry and consumer associations
\end{tabular}


Table A2. Type of actions to apply in stakeholder management with its Compliance evidence.

\begin{tabular}{cc}
\hline Type of Actions & Compliance Evidence \\
\hline Media appearances: interview, report, opinion piece & Media impact \\
Search for alliances & Agreement/Alliance \\
Mail to the neighbours & Letters delivered \\
Agreements & Signed agreement \\
Surveys & Results of the test \\
Sending informative email & Email sent \\
Installation of suggestion box & List of suggestions received and requests \\
for information \\
Information Days & Panels installed in the municipality \\
Expert Days & Report of the day \\
Press releases & Report of the day \\
Installation of information panels by municipalities & Media impact \\
Institutional events/communication (laying first stone, & Event Report \\
traveling exhibition installation...) & Forum Report \\
Participation in forums organized by the stakeholder & Social projects \\
Publication of information on the web & Report of the main milestones of the project \\
Information point mobile or in affected municipality & Number of visits and/or followers \\
Informative meeting and/or to collect contributions & Number of visits and list of suggestions received and \\
Technical meetings by phase & requests for information \\
Positioning and planning meeting (supra project) & Meeting Minutes \\
Press conference, meeting with media & Meeting Minutes \\
Field visit to other company facilities & Meeting Minutes \\
\end{tabular}

Table A3. Types of documentary support to execute the actions.

\begin{tabular}{c}
\hline Types of Documentary Support \\
\hline Argumenta document \\
Informative letter \\
Email \\
Schedule \\
Environmental technical documentation \\
Engineering Technical Documentation \\
Technical documentation of procedures and permits \\
Planning Document \\
Press dossier \\
Survey \\
Informative brochure \\
Audio visual material \\
Press release \\
Panels and informative posters \\
Project plans \\
Presentation \\
Project Web \\
Redlaboration Agreement Proposal \\
None
\end{tabular}

\section{References}

1. Delgado, S. Paisaje y Líneas Eléctricas: Sí, Pero Aquí no. Agenda Publica. EL País. 2019. Available online: http://agendapublica.elpais.com/paisaje-y-lineas-electricas-si-pero-no-aqui/ (accessed on 20 February 2020).

2. Vlek, C.; Keren, G. Behavioral Decision Theory and Environmental Risk Management: Assessment and Resolution of Four 'Survival' Dilemmas; Elsevier Science Publishers B.V: Amsterdam, The Netherlands, 1992. [CrossRef]

3. Miller, E.; William, R. Introducing Geo-Design: The Concept. Available online: https://www.esri.com/library/ whitepapers/pdfs/introducing-geodesign.pdf (accessed on 16 March 2020).

4. Moreno-Marimbaldo, F.-J.; Manso-Callejo, M.-Á.; Alcarria-Garrido, R. A Methodological Approach to Using Geodesign in Transmission Line Projects. Sustainability 2018, 10, 2757. [CrossRef]

5. Flaxman, M. GeoDesign: Fundamental Principles and Routes Forward. Talk at GeoDesign Summit. 2009. 
6. Dangermond, J. GIS: Designing Our Future ArcNews. Available online: http://www.esri.com/news/arcnews/ summer09articles/gis-designing-our-future.html (accessed on 16 March 2020).

7. Ervin, S.M. A System for GeoDesign. In Proceedings of the Digital Landscape Architecture Conference, Dessau, Germany, 2011; Available online: http://dl.icdst.org/pdfs/files/162ad3fb7c94f31a3ade9c3a866b1d79.pdf (accessed on 19 March 2020).

8. Sustainability-GRE. Available online: https://www.ree.es/es/sostenibilidad/compromiso-con-lasostenibilidad/grupos-de-interes (accessed on 20 February 2020).

9. PMBOK $^{\circledR}$, P. (n.d.). Project Management Institute. PMBOK ${ }^{\circledR}$ Guide (6th ed.). Available online: https://www.pmi.org/pmbok-guide-standards/foundational/pmbok (accessed on 20 February 2020).

10. Inspire-Grid-Project. Improved and Enhanced Stakeholders Participation in Reinforcement of Electricity Grid. 2013. Available online: http://www.inspire-grid.eu/index.php/inspire-grid-publications (accessed on 20 February 2020).

11. BESTGRID-Project. BESTGRID. 2014. Available online: http://www.bestgrid.eu/uploads/media/BESTGRID_ 1st_workshop_Main_messages.pdf (accessed on 20 February 2020).

12. RGI. Renewables Grid Initiative. 2009. Available online: https://renewables-grid.eu/about.html (accessed on 20 February 2020).

13. Freeman, R.-E.; Mcvea, J.-F. A Stakeholder Approach to Strategic Management. Darden Business School Working Paper No. 01-02. 2001. Available online: https://ssrn.com/abstract=263511 (accessed on 19 March 2020). [CrossRef]

14. Freeman, R.E. Stakeholder Management and Reputation. Values and Ethics for the 21st Century. 2012, pp. 363-381. Available online: https://www.bbvaopenmind.com/wp-content/uploads/2013/02/StakeholderManagement-and-Reputation_R.Edward-Freeman.pdf (accessed on 19 March 2020).

15. Cáceres, D.; Quintero, N.; Andrés, C. Stakeholders: A Corporate Sustainability Framework. Daena Int. J. Good Consci. 2015, 10, 94-108.

16. Globalreporting. Available online: https://www.globalreporting.org (accessed on 20 February 2020).

17. National-Grid, T. Available online: https:/www.nationalgridet.com/planning-together-riio/our-riio-2business-plan-2021-2026/stakeholder-engagement (accessed on 20 February 2020).

18. Eirgrid-Group. Available online: http://www.eirgridgroup.com/site-files/library/EirGrid/EirGridConsultation-Appendix-to-Grid-Strategy-(Download).pdf (accessed on 20 February 2020).

19. ELIA. Available online: https://www.elia.be/en/sustainability/community-involvement (accessed on 20 February 2020).

20. RTE. Available online: https://www.rte-france.com/en/article/rte-past-present (accessed on 20 February 2020).

21. Statnett. Available online: https://www.statnett.no/en/for-stakeholders-in-the-power-industry/ (accessed on 20 February 2020).

22. Tennet. Available online: https://www.tennet.eu/company/our-responsibility/stakeholders/ (accessed on 20 February 2020).

23. 50Hertz. Available online: https://www.50hertz.com/en/Company/Sustainability/Engagement (accessed on 20 February 2020).

24. Energinet.dk. Available online: https://en.energinet.dk/About-us/Governance/Corporate-socialresponsibility (accessed on 20 February 2020).

25. IFC. Stakeholder Engagement. 2019. Available online: https://www.ifc.org/wps/wcm/connect/ e03df4d4-223d-45d5-9bae-669cb162debd/Appendices.pdf?MOD=AJPERES\&CVID=jqeKR1D (accessed on 20 February 2020).

26. Zipf, M.; Kumar, S.; Scharf, H.; Zöphel, C.; Dierstein, C.; Möst, D. Multi-Criteria High Voltage Power Line Routing-An Open Source GIS-Based Approach. Int. J. Geo Inf. 2019, 8. [CrossRef]

27. Steinitz, C. A Framework for Geodesign: Changing Geography by Design; Esri Press: Redlands, CA, USA, 2012; ISBN 978-1589483330.

28. Flacke, J.; De Boer, C. An Interactive Planning Support Tool for Addressing Social Acceptance of Renewable Energy Projects in The Netherlands. Int. J. Geo Info. 2017, 6. [CrossRef]

29. Eikelboom, T.; Janssen, R. Comparison of Geodesign Tools to Communicate Stakeholder Values. Group Decis. Negot. 2015, 24, 1065-1087. [CrossRef] 
30. Cooper, S.C. Wiley Encyclopedia of Management, 3rd ed.; John Wiley \& Sons, Ltd.: Chichester, West Sussex, UK, 2014.

31. Mendelow, A.L. Environmental Scanning-The Impact of the Stakeholder Concept. ICIS 1981 Proceedings. International Conference on Information Systems. Association for Information Systems. AIS Electronic Library (AISeL). Available online: https://pdfs.semanticscholar.org/3579/ca37344c69961bbc2468ef9addf212200e39.pdf (accessed on 20 February 2020).

32. Usmani, F. Stakeholder Classification and Management Strategy. 21 November 2019. Available online: https://pmstudycircle.com/2012/06/stakeholder-analysis-stakeholder-management-strategy/ (accessed on 20 February 2020).

33. Hester, P.T.; Bradley, J.M.; Adams, K.M. Stakeholders in Systems Problems. Int. J. Syst. Syst. Eng. 2012, 3, 225-232. Available online: https://www.researchgate.net/profile/Kevin_Adams8/publication/264818485_ Stakeholders_in_systems_problems/links/54fd49160cf20700c5eaf4d2.pdf (accessed on 20 February 2020). [CrossRef]

34. Savage, G.T.; Nix, T.W.; Whitehead, C.J.; Blair, J.D. Strategies for Assessing and Managing Organizational Stakeholders. Acad. Manag. Perspect. 1991, 5, 61-75. [CrossRef]

35. Bohr, N. The Quantum Postulate and the Recent Development of Atomic Theory. Nature 1928, 121, 580-590. [CrossRef]

36. Freeman, R.E. The Politics of Stakeholder Theory: Some Future Directions. Bus. Ethics Q. 1994, 4, 409-421. [CrossRef]

37. Mitchell, R.; Agle, B.; Wood, D. Toward a Theory of Stakeholder Identification and Salience: Defining the Principle of Who and What Really Counts. Acad. Manag. Rev. 1997, 22, 853-886. Available online: https://www.jstor.org/stable/pdf/259247.pdf (accessed on 20 February 2020). [CrossRef]

38. Acuña, A.P. La Gestión de los Stakeholders: Análisis de los Diferentes Modelos; Encuentro Regional Zona Sur Adenag. Trelew 19 y 20 de abril de 2012; Universidad Nacional del Sur: Trelew, Argentina, 2012; Available online: http://repositoriodigital.uns.edu.ar/handle/123456789/4441 (accessed on 20 February 2020).

39. Mendelow, A. Environmental Scanning. In Proceedings of the 2nd International Conference on Information Systems, Cambridge, MA, USA, 7-9 December 1991.

40. Olander, S.; Landin, A. Evaluation of Stakeholder Influence in the Implementation of Construction Projects. Int. J. Proj. Manag. 2015, 23, 321-328. [CrossRef]

41. Gardner, J.; Rachlin, R.S.; Sweeny, A. Handbook of Strategic Planning; Allen Sweeny, H.W., Ed.; John Wiley \& Sons: New York, NY, USA, 1986.

42. Shamo, H.; Schumann, D.; Fischer, W.; Vögele, S.; Heinrichs, H.U.; Kuckshinrichs, W. Changing Attitudes and Conflicting Arguments: Reviewing Stakeholder Communication on Electricity Technologies in Germany. Energy Res. Soc. Sci. 2019, 55, 106-121. [CrossRef]

43. Simoncic, M.; Žurga, G. Social Responsible Communication of Nuclear Power Plant with External Stakeholders. Int. J. Nucl. Power Energy Policy Econ. Law 2016, 61, 653-659.

44. Dalcher, D. Further Advances in Project Management: Guided Exploration in Unfamiliar Landscapes; Routledge: Abingdon, UK, 2016.

45. Giuffrida, N.; Pira, M.L.; Inturri, G.; Ignaccolo, M. Mapping with Stakeholders: An Overview of Public Participatory GIS and VGI in Transport Decision-Making. Int. J. Geo Inf. 2019, 8. [CrossRef]

46. Kuzmin, O.; Khilukha, O. Regulation of Stakeholders' Interests in Corporate Governance through Negotiations. Economic Annals-XXI 2016, 161, 56-60. Available online: https://core.ac.uk/download/ pdf/153586689.pdf (accessed on 19 March 2020). [CrossRef]

47. SEC. Sede Electrónica del Catastro. 2019. Available online: http://www.sedecatastro.gob.es (accessed on 20 February 2020).

(C) 2020 by the authors. Licensee MDPI, Basel, Switzerland. This article is an open access article distributed under the terms and conditions of the Creative Commons Attribution (CC BY) license (http://creativecommons.org/licenses/by/4.0/). 